\title{
Hot Isostatic Pressing of Chevrel Phase Bulk and Hydrostatically Extruded Wire Samples
}

\author{
Tomas C. Willis, Paul D. Jablonski* and David C. Larbalestier \\ Applied Superconductivity Center and Department of Materials Science and Engineering, \\ University of Wisconsin-Madison, 1500 Johnson Drive, Madison, WI 53706 U.S.A \\ * Current address: Teledyne Wah-Chang Albany, Albany, OR 97321 U.S.A.
}

Sylvie Even-Boudjada, Roger Chevrel and Marcel Sergent

Chimie du Solide et Inorganique Moléculaire, URA CRNS 1495, Université de Rennẹs-I, 35042 Rennes Cêdex France

\begin{abstract}
In order to lower final sintering temperatures for Chevrel phase (CP) wires, we have investigated low-temperature hot isostatic pressing (HIP'ing) of both bulk and wire samples. We have fabricated (Pb,Sn)-based Chevrel phase (CP) monofilament and 61 filament wires by hydrostatic extrusion of (Cu or $\mathrm{Cu}-\mathrm{Ni}) /(\mathrm{Nb}$ or $\mathrm{V}$ )/CP composites, followed by cold drawing. We have investigated the $\mathrm{CP} /$ barrier reaction during heat treatment, finding $\mathrm{V}$ is unsuitable, but $\mathrm{Nb}$ is suitable at these lower temperatures for prereacted $\mathrm{Pb}_{1-x} \mathrm{Sn}_{x} \mathrm{Mo}_{6} \mathrm{~S}_{8}$ cores. We prepared powders of the binary Chevrel phase $\mathrm{Mo}_{6} \mathrm{~S}_{8}$ by acid leaching of $\mathrm{Li}_{x} \mathrm{Mo}_{6} \mathrm{~S}_{8}$ and $\mathrm{Ni}_{x} \mathrm{Mo}_{6} \mathrm{~S}_{8}$. We prepared bulk samples of $\mathrm{PbMo}_{\epsilon} \mathrm{S}_{8}$ and $\mathrm{Pb}_{1-x} \mathrm{Sn}_{x} \mathrm{Mo}_{6} \mathrm{~S}_{8}$ by HIP'ing mixtures of " $\mathrm{Pb}+\mathrm{Mo}_{6} \mathrm{~S}_{8}$ " powders (in situ route) or by prereacting $\mathrm{Pb}, \mathrm{Sn}$ and $\mathrm{Mo}_{\epsilon} \mathrm{S}_{8}$ powders before $\mathrm{HIP}$ 'ing (prereacted route). The in situ powders were HIP'ed under different time-temperature-pressure conditions up to $12 \mathrm{~h} / 600{ }^{\circ} \mathrm{C} / 200 \mathrm{MPa}$, producing partially consolidated $\mathrm{PbMo}_{6} \mathrm{~S}_{8}$ samples. Further HIP'ing of all samples at temperatures of 700,800 and $1000^{\circ} \mathrm{C}, 200 \mathrm{MPa}$ pressure and times of 8 and 80 hours produced additional consolidation, up to $95 \%$ of full density. As the aggressiyeness (temperature and time under pressure) of the HIP process increased, the density, hardness, critical temperature, and magnetization critical current density increased.
\end{abstract}

\section{INTRODUCTION}

The promise of the ternary molybdenum sulfide superconductors is the high measured values of upper critical field $\left(B_{c_{2}}\right)[1],[2]$, which suggests that very high critical current densities $\left(J_{c}\right)$ should be achieved if only the right flux-pinning microstructure can be produced. A number of workers have shown that, particularly

Manuscript received October 17, 1994.

T. C. Willis, e-mail tomasecae.risc.edu, FAX 608-263-1087; D. C. Larbalestier, e-mail larbalesQengr.wisc.edu, FAX 608-263-1087.

Support was provided by the U.S. Department of Energy, Division of High Energy Physics. Further support was provided in part by the IMR, Madison, WI, through NIH Biomedical Research Technology Grant RR 00570. Additional support was provided by the Ministère Français de la Recherche et de la Technologie (contract MRT 88 W 508 ) and by A.D.E.M.E. (for S. E.-B.). at lower fields, grain-boundary pinning controls $J_{c}$ in $\mathrm{PbMo}_{6} \mathrm{~S}_{8}$ and $\mathrm{SnMo}_{6} \mathrm{~S}_{8}$ bulk samples[3], [4]. However, efforts to make prototype wires suitable for high-field magnets have been hampered by insufficient $J_{c}$ values $\left(J_{c}(20 \mathrm{~T}) \approx 200 \mathrm{~A} / \mathrm{mm}^{2}[5]-[8]\right)$ and reaction barrier problems.

Improvements in the small-cation leaching technique can now produce submicron $\mathrm{Mo}_{6} \mathrm{~S}_{8}$ powders with a narrow grain size distribution[9], [10]. These $\mathrm{Mo}_{6} \mathrm{~S}_{8}$ powders, when mixed with $\mathrm{Pb}$ and reacted to form $\mathrm{PbMo}_{6} \mathrm{~S}_{8}$, can retain a small and narrow particle size distribution, in contrast to most other $\mathrm{PbMo}_{6} \mathrm{~S}_{8}$ samples prepared by powder processing. In order to raise $\mathrm{PbMo}_{6} \mathrm{~S}_{8} J_{c}$ values, we have set out to combine the proven consolidation technique of hot isostatic pressing[5], [11] with ultrafine $\mathrm{Mo}_{6} \mathrm{~S}_{8}$ powders mixed with $\mathrm{Pb}$, using temperatures as low as possible, to inhibit grain growth and preserve $J_{c}$.

This paper describes attempts to address the problems of insufficient $J_{c}$ and barrier reaction effects by using lower final HIP reaction temperatures on samples made from fine-grained, small-particle-size $\mathrm{Mo}_{6} \mathrm{~S}_{8}$ powders.

\section{Experimental Procedure}

\section{A. Wires}

Approximately $3 \mu \mathrm{m} \mathrm{Pb} \mathrm{Pb}_{1-x} \mathrm{Sn}_{x} \mathrm{Mo}_{6} \mathrm{~S}_{8}$ powders were prepared from elemental powders using techniques previously described[11]. Wires were fabricated by the hydrostatic extrusion of prereacted $\mathrm{Pb}_{1-x} \mathrm{Sn}_{x} \mathrm{Mo}_{6} \mathrm{~S}_{8}$ powders in $\mathrm{Cu}$ or $\mathrm{Cu} 30 \% \mathrm{Ni}$ cans. We found that the CP cores exhibited better shape stability after extrusion when the powders were uniaxially pressed into the billets and the composites discussed in this paper were prepared in this fashion. Both $\mathrm{Nb}$ and $\mathrm{V}$ barriers were used to protect the Chevrel phase core from the $\mathrm{Cu}$-based sheath. Billets were warm hydrostatically extruded from $15.7 \mathrm{~mm}$ to $5.1 \mathrm{~mm}$ diameter at $250^{\circ} \mathrm{C}$. These monofilaments were drawn either to $1.4 \mathrm{~mm}$ hexagonal rod for stacking, to $0.91 \mathrm{~mm}$ diameter for testing, or to failure. The hexagonal rods were stacked in a $\mathrm{Cu}-\mathrm{Ni}$ can, re-extruded and drawn to failure. Fig. 1 shows a cross-section of an extruded multifilamentary wire (B32) at a diameter of $3.4 \mathrm{~mm}$.

Short lengths $(76 \mathrm{~mm})$ of $2.5 \mathrm{~mm}$ diameter Nb-barrier (B30) and V-barrier (B31) wires were vacuum sealed in 


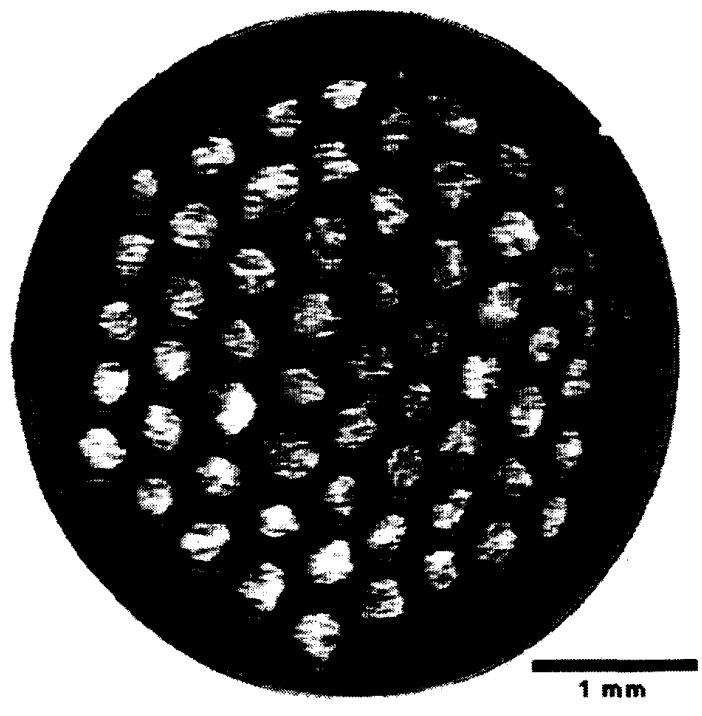

Fig. 1. Backscattered electron micrograph of hydrostatically extruded 61-filament $\mathrm{CP} / \mathrm{V} / \mathrm{Cu}-\mathrm{Ni}$ composite.

quartz glass and heat treated for 2-143 hours at 430,540 , 650 and $800^{\circ} \mathrm{C}$ in order to study the barrier-core intergrowth reactions. A longer length of $0.91 \mathrm{~mm}$ diameter Nb-barrier wire (B24) was HIP'ed for 12 hours at $800^{\circ} \mathrm{C}$ under $200 \mathrm{MPa}$ in order to study consolidation and the barrier-core intergrowth under pressure.

\section{B. Bulk samples}

Bulk samples of $\mathrm{PbMo}_{6} \mathrm{~S}_{8}$ were prepared from $\mathrm{Mo}_{6} \mathrm{~S}_{8}+\mathrm{Pb}$ powders derived from acid-leached $\mathrm{Li}_{x} \mathrm{Mo}_{6} \mathrm{~S}_{8}$ and hydrogen-reduced $\mathrm{PbS}$, following procedures described in [10]. These powders, used for samples RMS1RMS6, were prepared at the University of Rennes. The second $\mathrm{Mo}_{6} \mathrm{~S}_{8}$ powder type, used for sample WMS1, was made from acid-leached $\mathrm{Ni}_{2} \mathrm{Mo}_{6} \mathrm{~S}_{8}$ powders at the University of Wisconsin. The WMS1 powders were prereacted with $\mathrm{Pb}+\mathrm{Sn}$ powders for $12 \mathrm{~h}$ at $1000^{\circ} \mathrm{C}$ to make $\mathrm{Pb}_{0.8} \mathrm{Sn}_{0.2} \mathrm{Mo}_{6} \mathrm{~S}_{8}$.

RMS1 and RMS2 $\mathrm{Pb}+\mathrm{Mo}_{6} \mathrm{~S}_{8}$ powders were reacted in situ in Mo-lined stainless steel canisters for 2 and $12 \mathrm{~h}$, respectively, at $600{ }^{\circ} \mathrm{C}$ using different time-temperaturepressure profiles in the hot isostatic press. As the initial HIP'ing produced insufficiently densified samples, RMS1 was re-HIP'ed for $8 \mathrm{~h}$ at $700^{\circ} \mathrm{C}$ and $800^{\circ} \mathrm{C}$ to make RMS3 and RMS4, respectively. RMS2 was re-HIP'ed at $1000^{\circ} \mathrm{C}$ for 8 and 80 hours to make RMS5 and RMS6, respectively. The prereacted $\mathrm{Pb}_{0.8} \mathrm{Sn}_{0.2} \mathrm{Mo}_{6} \mathrm{~S}_{8}$ powders were HIP'ed with the same HIP parameters at RMS5 to make WMS1. All HIP runs used a pressure of $200 \mathrm{MPa}$. Table I summarizes the HIP treatment schedules.
TABLE I.

SUMMARY OF HIP PARAMETERS FOR BULK SAMPLES.

\begin{tabular}{lcc}
\hline Sample & $\begin{array}{c}\text { Maximum } \\
\text { temperature }\left({ }^{\circ} \mathrm{C}\right)\end{array}$ & $\begin{array}{c}\text { Time at } \\
\text { pressure }(\mathrm{h})\end{array}$ \\
\hline RMS1 & 600 & 2 \\
RMS2 & 600 & 12 \\
RMS3 & 700 & 8 \\
RMS4 & 800 & 8 \\
RMS5 & 1000 & 8 \\
RMS6 & 1000 & 80 \\
WMS1 & 1000 & 8 \\
\hline
\end{tabular}

Critical temperature $\left(T_{c}\right)$ was measured by AC susceptometry. Microhardness was measured with Vickers hardness and the microstructure was observed with light microscopy (LM), electron microprobe, conventional and high-resolution scanning electron microscopy (SEM). Powder X-ray diffraction (XRD) was used to find impurity phases.

\section{RESULTS}

\section{A. Wires}

1) Consolidation: Prior to extrusion the powder $\mathrm{Pb}_{1-x} \mathrm{Sn}_{x} \mathrm{Mo}_{6} \mathrm{~S}_{8}$ cores of the wires were $\approx 65 \%$ dense, but after the hydrostatic extrusion the density was greater than $97 \%$. Although fully densified $\mathrm{Pb}_{1-x} \mathrm{Sn}_{x} \mathrm{Mo}_{6} \mathrm{~S}_{8}$ has a microhardness of $\approx 450-500 \mathrm{VHN}$, microhardness indentations spanning the weakly connected grains in the wire cores yielded values of $100-250$ VHN for the asextruded and as-drawn cores. The HIP'ed wire sample (B24) achieved $\approx 99 \%$ density.

2) Barrier-core reactions: Electron microprobe analysis with semiquantitative wavelength dispersive spectroscopy was used to analyze the composition of the cores of HIP'ed and pressureless sintered $\mathrm{Nb}$-sheathed and $\mathrm{V}$-sheathed $\mathrm{Pb}_{1-x} \mathrm{Sn}_{x} \mathrm{Mo}_{6} \mathrm{~S}_{8}$-cored wires. In all $\mathrm{Nb}$-sheathed cross-sections where a break in the barrier was evident, $\mathrm{Cu}_{x>1} \mathrm{Mo}_{6} \mathrm{~S}_{8}$ grains were found amongst $\mathrm{Pb}_{1-x} \mathrm{Sn}_{x} \mathrm{Mo}_{6} \mathrm{~S}_{8}$ and $\mathrm{MoS}_{2}$ grains. Near the breaks, $\mathrm{Cu}_{0.65} \mathrm{NbS}_{2}$ was identified on the stabilizer side of the $\mathrm{Nb}$ barrier. Copper was always present in any intergrowth phases and was always traced to a nearby break in the barrier.

Microscopy showed that the $\mathrm{V}$ quickly reacted with the core, creating layers of insulating vanadium sulfides, even at temperatures $\left(\leq 800^{\circ} \mathrm{C}\right)$ where negligible $\mathrm{Nb}$ intergrowth was found. As shown in table II, even a two hour heat treatment at $800{ }^{\circ} \mathrm{C}$ created a $\sim 10 \mu \mathrm{m}$ thick intergrowth layer.

3) Cold work and $T_{c}$ : Lattice instabilities due to cold work have been linked to large reductions in $T_{c}$ for CP in [12], while [1] showed a large increase in $\Delta T_{c}$ for coldworked samples. For the present wire samples, a similar 
TABLE II.

BARRIER-CORE INTERGROWTH LAYER THICKNESS FOR HEAT TREATED V-SHEATHED WIRES (B31).

\begin{tabular}{lll}
\hline $\begin{array}{l}\text { Heat treatment } \\
\text { Time (hours) }\end{array}$ & Temperature $\left({ }^{\circ} \mathrm{C}\right)$ & $\begin{array}{l}\text { Reaction layer } \\
\text { thickness }(\mu \mathrm{m})\end{array}$ \\
\hline 2 & 430 & 0 \\
2 & 650 & $7-8$ \\
2 & 800 & $8-10$ \\
24 & 800 & $10-15$ \\
\hline
\end{tabular}

degradation of $T_{c}$ and $\Delta T_{c}$ was found, as shown in Fig. 2. In the as-drawn wire, the core particles are not chemically bonded and are electromagnetically granular, as the large field dependence of $\chi_{a c}^{\prime}(\mathrm{T})$ shows. After heat treatment, core particles sinter together, $\Delta T_{c}$ dropped and the field sensitivity was greatly reduced, although $T_{c}$ remains depressed.

\section{B. Bulk samples}

1) Microscopy: Samples RMS1 and RMS2 were only poorly densified by the HIP, while RMS3-RMS6 and WMS1 were densified to closed-pore density $(\approx 92 \%)$. While RMS1 is denser than a typical pressureless sintered sample (compare Fig. 3 to Fig. $4 b$ in [11]), it is not fully densified. RMS1 and RMS2 have a $\approx 105 \mu \mathrm{m}$ thick ring of denser $(\approx 92 \%) \mathrm{PbMo}_{6} \mathrm{~S}_{8}$ around the outer edge. This densification gradient through the sample indicates that the HIP time-pressure-temperature profile was not optimized for the sample size and sintering parameters[13].

As aggressiveness of the HIP treatments increased, the average grain size, calculated by the line intercept method, increased, as did the density. The average grain

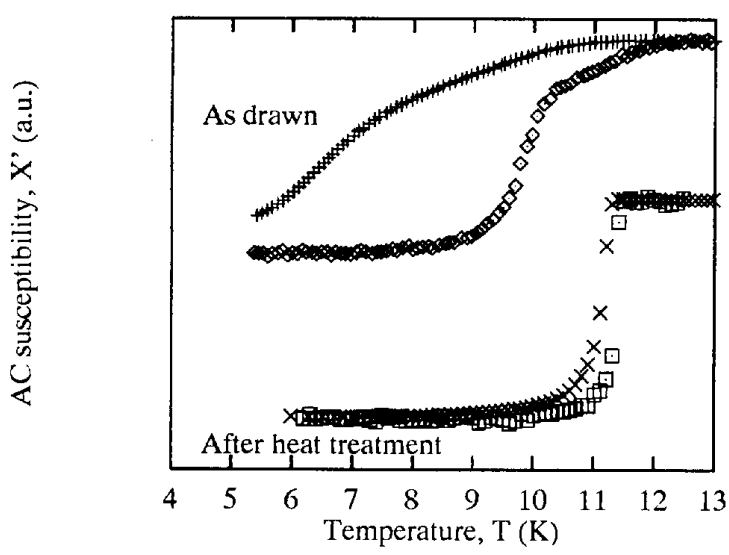

Fig. 2. AC susceptibility, $\chi_{a c}^{\prime}(\mathrm{T})$, for as-drawn $\left(\diamond b_{a c}=50 \mu \mathrm{T}\right.$; $\left.+b_{a c}=2 \mathrm{mT}\right)$ and post-heat treatment $\left(\square b_{a c}=20 \mu \mathrm{T} ; \times b_{a c}=2 \mathrm{mT}\right)$ wire samples $B 31$. The $\chi_{a c}^{\prime}(T)$ traces for the different wire conditions are offset for clarity.

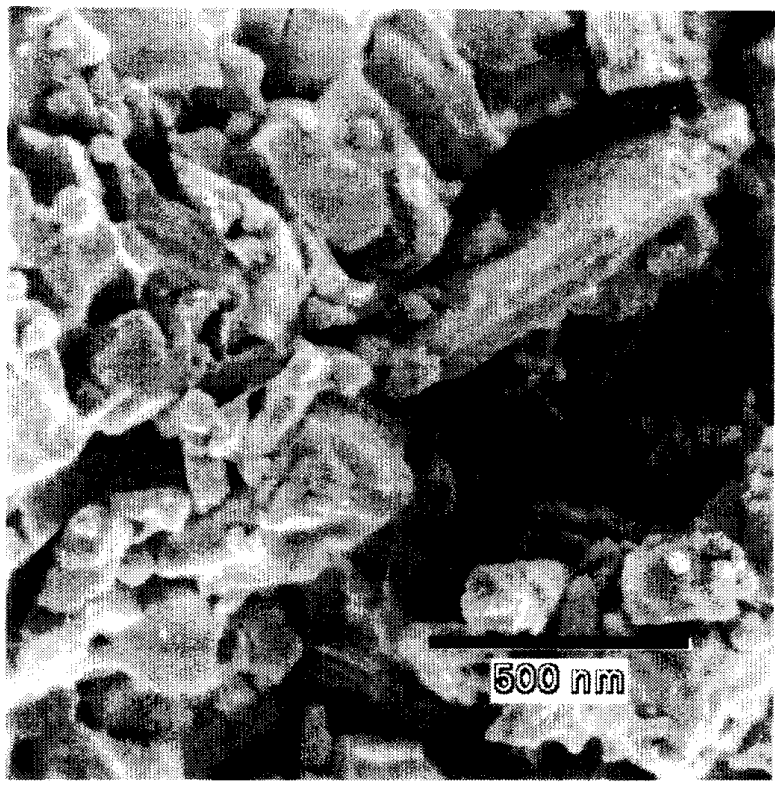

(a) RMS1.

Fig. 3. High-resolution secondary electron fractograph of poorly HIP'ed bulk sample RMS1, given a $2 \mathrm{~h}$ HIP cycle at $600^{\circ} \mathrm{C}$ under $200 \mathrm{MPa}$.

size values, $\mathrm{d}_{\text {ave }}$, are summarized in table III. The density, estimated from micrographs and volumetric measurements, increased from $\approx 74 \%$ in RMS1 to $\approx 95 \%$ in RMS6. The density of WMS1 was $\approx 92 \%$. Vickers microhardness values, taken with a $200 \mathrm{~g}$ load for $15 \mathrm{~s}$, increased from $\approx 100 \mathrm{VHN}$ for sample RMS1 through $\approx 190 \mathrm{VHN}$ for RMS3 to $\approx 370 \mathrm{VHN}$ for RMS6, and are summarized in table III.

2) X-ray diffraction: X-ray diffractograms of samples RMS1-RMS4 and WMS1 showed no traces of impurity phases. However, $\mathrm{MoS}_{2}$ was detected in small amounts in RMS5 and RMS6, although it was not readily apparent in high-resolution SEM examinations of fracture surfaces.

3) Critical temperatures: Critical temperatures were measured by AC susceptometry. Table III shows the midpoint $T_{c}$ and transition widths ( $\Delta T_{c}$, measured from $10 \%$ to $90 \%$ of the $\chi_{a c}^{\prime}$ signal) for the bulk samples, measured at an applied field of $0.2 \mathrm{mT}$.

4) Critical current densities: Fig. 4 shows the $4.2 \mathrm{~K}$ $J_{c m}$ (B) values for the bulk samples. Using roughly rectangular samples of dimensions $\ell_{1} \times \ell_{2} \times h$, where $\ell_{1} \leq \ell_{2}$ are perpendicular to the applied magnetic field, $J_{c}$ is calculated from the magnetization (M) curves as

$$
J_{c}=\frac{3}{2} \ell_{1}\left(1-\frac{\ell_{1}}{3 \ell_{2}}\right) \Delta M
$$


TABLE III.

AVERAGE GRAIN SIZE, MICROHARDNESS AND CRJTICAL TEMPERATURES OF HIP'ED BULK SAMPLES.

\begin{tabular}{lcccc} 
Sample & $\begin{array}{c}\mathrm{d}_{\text {ave }} \\
\text { (nm) }\end{array}$ & $\begin{array}{c}\text { Microhardness } \\
\text { (VHN) }\end{array}$ & $\begin{array}{c}T_{\text {c50 }} \\
(\mathrm{K})\end{array}$ & $\begin{array}{c}\Delta T_{\text {c10-90 }} \\
(\mathrm{K})\end{array}$ \\
\hline RMS1 & 89 & 97 core $/ 153$ ring & 12.30 & 0.90 \\
RMS2 & n.a. & 128 core $/ 220$ ring & 12.38 & 0.85 \\
RMS3 & 119 & 188 & 13.30 & 0.60 \\
RMS4 & n.a. & too friable & 13.50 & 0.56 \\
RMS5 & 143 & 266 & 13.19 & 0.30 \\
RMS6 & n.a. & 373 & 13.46 & 0.37 \\
WMS1 & 630 & 206 & $13.55^{\mathrm{b}}$ & $0.95{ }^{\mathrm{b}}$ \\
\hline
\end{tabular}

"n.a." indicates data not available at this time.

aSample RMS4 was too friable for accurate microhardness determination.

${ }^{\mathrm{b}} T_{c}$ determined from SQUID magnetic moment $v s$. temperature data at $2 \mathrm{mT}$.

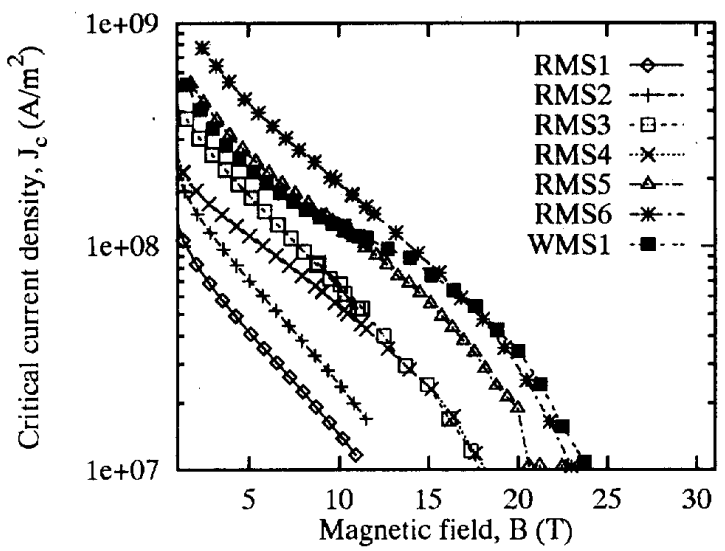

Fig. 4. Magnetization critical current densities $\left(J_{c m}(B)\right)$ for bulk samples.

5) Irreversibility line: Fig. 5 shows the $B_{\text {irr }}(\mathrm{T})$ data for the bulk samples. $B_{\text {irr }}$ is taken as the intersection of the extrapolated field-increasing and field-decreasing legs of the irreversible magnetization curve, as in [14].

\section{Discussion}

\section{A. Choice of barrier material}

Although V seemed to be a plausible candidate for barrier material, from a hardness and workability standpoint, the reaction between $\mathrm{CP}$ cores and the $\mathrm{V}$ barrier is much more severe than in the case of $\mathrm{Nb}$. Niobium, on the other hand, is not greatly attacked by the prereacted core at temperatures $\leq 800^{\circ} \mathrm{C}$, in contrast to results for cores which are reacted in situ[15].

\section{B. Consolidation}

Even though wire cores hundreds of microns across can be HIP'ed to full density at $800^{\circ} \mathrm{C}$, large bulk samples

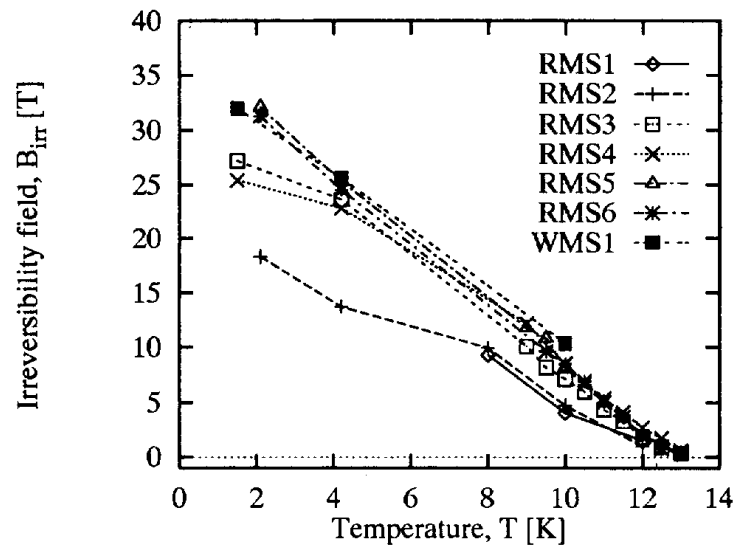

Fig. 5. Irreversibility fields $\left(B_{\text {irr }}(\mathrm{T})\right)$ for bulk samples.

(e.g. $10 \mathrm{~mm}$ diameter $\times 30 \mathrm{~mm}$ ) of in situ $\mathrm{PbMo}_{6} \mathrm{~S}_{8}$ cannot be, except in a narrow rim. Wire filaments the size of the densified rims of RMS1 and RMS2, however, should be fully densified under these same lower temperature $\left(600^{\circ} \mathrm{C}\right) \mathrm{HIP}$ conditions. Grain size only increased from $\approx 89 \mathrm{~nm}$ to $\approx 143 \mathrm{~nm}$ in $80 \mathrm{~h}$ at $1000^{\circ} \mathrm{C}$ the Li-based bulk samples, while it is rather larger $(630 \mathrm{~nm})$ in the Nibased samples. Despite the fine CP grains, we were not able to get the full densification achieved in [4], [11], [14] with larger prereacted elemental powders.

Microhardness for the bulk samples was rather low, in contrast to the microhardness value of $450 \mathrm{VHN}$ for the $\mathrm{Pb}_{0.1} \mathrm{Sn}_{0.9} \mathrm{Mo}_{6} \mathrm{~S}_{7.6}$ sample HIP'ed at $800{ }^{\circ} \mathrm{C}$ discussed in [11]. This suggests that our HIP profiles are insufficient for the bulk consolidation of these samples.

\section{Critical temperature}

$T_{c}$ increases with increasingly aggressive HIP treatments for RMS1-RMS6, suggesting that that we have not optimized the $\mathrm{PbMo}_{6} \mathrm{~S}_{8}$ phase formation, leaving the $\mathrm{PbMo}_{6} \mathrm{~S}_{8}$ chemically inhomogeneous and/or incompletely reacted, a trend [16] found for uniaxially hot-pressed samples. WMS1, HIP'ed with prereacted $\mathrm{Pb}_{0.8} \mathrm{Sn}_{0.2} \mathrm{Mo}_{6} \mathrm{~S}_{8}$ already contained well-formed CP before HIP'ing.

\section{Critical current density}

Increasingly aggressive HIP'ing led to increasing microhardness, density and $J_{c}$ in samples RMS1-RMS6. Furthermore, the $J_{c}$ values of RMS6 are slightly smaller than those of typical samples HIP'ed at $800^{\circ} \mathrm{C}[11]$, and almost an order of magnitude lower than those of the best HIP'ed samples[5], [6], [14], although RMS6 is not as fully densified as the best samples.

We can be encouraged because the $J_{c}$ values of the RMS1 sample is $\approx 2$ times larger than typical values for samples sintered without pressure at temperatures of 800 
$1100^{\circ} \mathrm{C}[11]$. Such sintered samples have a porous microstructure, like the cores of RMS1 and RMS2, but also have larger grain sizes and grain size distributions.

Just as microhardness did not reach expected values, critical current densities increased greatly with densification, but never reached the $200 \mathrm{~A} / \mathrm{mm}^{2}$ at $20 \mathrm{~T}$ benchmark previously set[5]-[8]. We believe that the $J_{c}$ values

- were low due to insufficient densification. $\mathrm{MoS}_{2}$ impurities in samples RMS5 and RMS6 may also have lowered $J_{c}$.

\section{E. Irreversibility line}

Unlike the $\mathrm{PbMo}_{6} \mathrm{~S}_{8}$ samples studied in [17], which display an exponential behavior of $B_{\text {irr }}(T)$, these bulk samples display an approximately linear functionality with temperature. This non-exponential character of the irreversibility line suggests that $J_{c}$ is not limited by granularity. This point, taken with the low microhardness and density values, leads us to conclude that $J_{c}$ is limited by incomplete consolidation. Considering that $B_{\text {irr }}(\mathrm{T})$ is rather low for these $\mathrm{PbMo}_{6} \mathrm{~S}_{8}$ samples, it is not surprising that $J_{c}(\mathrm{~B})$ is lower than the best $\mathrm{PbMo}_{6} \mathrm{~S}_{8}$ samples.

\section{Conclusions}

From the results presented in this paper, we draw these conclusions:

- Vanadium is not a suitable reaction barrier for Chevrel phases.

- Niobium does not have significant reaction with prereacted $\mathrm{CP}$ at temperatures $\leq 800^{\circ} \mathrm{C}$ and is a good reaction barrier at these temperatures.

- Wire cores $\approx 100 \mu \mathrm{m}$ across can be fully consolidated by HIP'ing at temperatures $\leq 800^{\circ} \mathrm{C}$.

- HIP'ed in situ $\mathrm{PbMo}_{6} \mathrm{~S}_{8}$ has little grain growth at temperatures $\leq 1000^{\circ} \mathrm{C}$.

- We have not optimized HIP parameters for in situ $\mathrm{Pb}+\mathrm{Mo}_{6} \mathrm{~S}_{8}$.

Expect further increases in $J_{c}$ for $\mathrm{Mo}_{6} \mathrm{~S}_{8}$-based CP samples as HIP parameters are optimized and impurities such as $\mathrm{MoS}_{2}$ are eliminated.

\section{ACKNOWLEDGMENT}

High-field VSM measurements were performed at the Frances Bitter National Magnet Laboratory with the assistance of Ed McNiff. Electron microprobe measurements were performed at the University of Chicago, Department of Geophysics with the assistance of Dr. Ian Steele. The authors gratefully acknowledge Ya Chen at the IMR and Nik Ingle, Brian Gerred and Brian Johnson at the ASC. The authors also thank L. Burel for her collaboration in powder preparation.

\section{REFERENCES}

[1] Ø. Fischer, R. Odermatt, G. Bongi, H. Jones, R. Chevrel, and $M$. Sergent, "On the superconductivity in the ternary molybdenum sulfides," Phys. Lett. A, vol. 45A, Sept. 1973, pp. 8788.

[2] S. Foner, E. G. McNiff Jr., and E. J. Alexander, "600 kG superconductors," Phys. Lett. A, vol. 49A, 1974, pp. 269-270

[3] C. Rossel and $\emptyset$. Fischer, "Critical current densities in bulk Chevrel-Phase samples," J. Phys. F, vol. 14, 1984, pp. 455472.

[4] L. A. Bonney, T. C. Willis, and D. C. Larbalestier, "Grain size dependence of critical current densities in hot isostatically pressed $\mathrm{SnMo}_{6} \mathrm{~S}_{8}$, IEEE Trans. Appl. Superconductivity, vol. 3, Mar. 1993, pp. 1582-1585.

[5] H. Yamasaki, M. Umeda, S. Kosaka, Y. Kimura, T. C. Willis, and D. C. Larbalestier, "Poor intergrain connectivity of $\mathrm{PbMo}_{6} \mathrm{~S}_{8}$ in sintered Mo-sheathed wires and the beneficial effect of hot-isostatic pressing treatments on the transport critical current density," J. Appl. Phys., vol. 70, Aug. 1991, pp. 1606-1613.

[6] G. Rimikis, W. Goldacker, W. Specking, and R. Flükiger, "Critical currents in $\mathrm{Pb}_{1.2-x} \mathrm{Sn}_{x} \mathrm{Mo}_{6} \mathrm{~S}_{8}$ wires," IEEE Trans. Mag., vol. 27, Mar. 1991, pp. 1116-1119.

[7] P. Rabiller, P. Genevey, M. Decroux, R. Chevrel, M. Sergent, L. Le Lay, and P. Dubots, "Promising advances in the elaboration of superconducting $\mathrm{PbMo}_{6} \mathrm{~S}_{8}$-based wires," Mater. Lett., vol. 15, 1992, pp. 19-25.

[8] Y. Kubo, F. Uchikawa, S. Utsunomiya, K. Noto, K. Katagiri, and N. Kobayashi, "Frabrication and evaluation of small coils using $\mathrm{PbMo}_{6} \mathrm{~S}_{8}$ wires." Cryogenics, 1993, pp. 883-888.

[9] P. Selvam, D. Cattani, J. Cors, P. Niedermann, S. Ritter, $\emptyset$. Fischer, P. Rabillier, and R. Chevrel, " $T_{c}$ variation in $\mathrm{PbMo}_{6} \mathrm{~S}_{8}$ : A critical analysis and a comparison with pure phases," Mater. Res. Bull., vol. 26, 1991, pp. 1151-1165.

[10] P. Rabiller, M. Rabiller-Baudry, s. Even-Boudjada, L. Burel, R. Chevrel, M. Sergent, M. Decroux, J. Cors, and J. L. Maufras, Mater. Res. Bull., vol. 29, May 1994, pp. 567-574.

[11] L. Le Lay, T. C. Willis, and D. C. Larbalestier, "Fully connected bulk $\mathrm{Pb}_{1-x} \mathrm{Sn}_{x} \mathrm{Mo}_{6} \mathrm{~S}_{7.6}$ samples made by hot isostatic pressing," Appl. Phys. Lett., vol. 60, Feb. 1992, pp. 775-777.

[12] P. Müller and M. Rohr, "Lattice instability of superconducting cold-worked core-wires on the base of $\mathrm{PbMo}_{5} \mathrm{~S}_{6}$, "Phys. Status Solidi $A$, vol. 43, 1977, pp. K19-K22.

[13] W.-B. Li, M. F. Ashby, and K. E. Easterling, "On densification and shape change during hot isostatic pressing," Acta Met., vol. 35, no. 12, 1987, pp. 2831-2842.

[14] L. A. Bonney, T. Willis, and D. Larbalestier, "Dependence of critical current density of microstructure in the $\mathrm{SnMo}_{6} \mathrm{~S}_{8}$ Chevrel phase superconductor," unpublished.

[15] P. Rabiller, R. Chevrel, M. Sergent, D. Ansel, and M. Bohn, "Niobium antidiffusion barrier reactivity in tin-doped, in situ $\mathrm{PbMo}_{6} \mathrm{~S}_{8}$-based wires," J. Alloys and Compounds, 1992.

[16] P. Selvam, D. Cattani, J. Cors, M. Decroux, A. Junod, P. Niedermann, S. Ritter, $\emptyset$. Fischer, P. Rabbiler, and R. Chevrel, "Superconductung, microstrctural, and grain boundary properties of hot-pressed $\mathrm{PbMo}_{6} \mathrm{~S}_{8}, "$ J. Appl. Phys., vol. 72, no. 9, 1992, pp. 4232-4239.

[17] C. Rossel, O. Peña, H. Schmitt, and M. Sergent, "On the irreversibility line in the Chevrel phase superconductors," Physica $C$, vol. 181, 1991, pp. 363-368. 